\title{
Lumbar spine and total-body dual-energy X-ray absorptiometry in children with severe neurological impairment and intellectual disability: a pilot study of artefacts and disrupting factors
}

\author{
S. Mergler • R. Rieken • D. Tibboel • H. M. Evenhuis • \\ R. R. van Rijn • C. Penning
}

Received: 11 April 2011 /Revised: 15 September 2011 / Accepted: 17 September 2011 / Published online: 18 January 2012

(C) The Author(s) 2012. This article is published with open access at Springerlink.com

\begin{abstract}
Background Children with severe neurological impairment and intellectual disability (ID) are susceptible for developing low bone mineral density (BMD) and fractures. BMD is generally measured with dual-energy X-ray absorptiometry (DXA).

Objective To describe the occurrence of factors that may influence the feasibility of DXA and the accuracy of DXA outcome in children with severe neurological impairment and ID.

Materials and methods Based on literature and expert opinion, a list of disrupting factors was developed. Occurrence of these factors was assessed in 27 children who underwent DXA measurement.

Results Disrupting factors that occurred most frequently were movement during measurement (82\%), aberrant body composition (67\%), small length for age $(56 \%)$ and scoliosis (37\%). The number of disrupting factors
\end{abstract}

S. Mergler $(\bowtie) \cdot$ R. Rieken $\cdot$ H. M. Evenhuis $\cdot$ C. Penning Intellectual Disability Medicine/Department of General Practice, Erasmus University Medical Centre,

PO Box 2040, 3000 CA Rotterdam, The Netherlands

e-mail: s.mergler@erasmusmc.nl

D. Tibboel

Department of Pediatric Surgery,

Erasmus University Medical Centre,

Rotterdam, The Netherlands

R. R. van Rijn

Department of Radiology, Academic Medical Centre,

Amsterdam, The Netherlands per child was mean 5.3 (range 1-8). No correlation was found between DXA outcomes and the number of disrupting factors.

Conclusion Factors that may negatively influence the accuracy of DXA outcome are frequently present in children with severe neurological impairment and ID. No systematic deviation of DXA outcome in coherence with the amount of disrupting factors was found, but physicians should be aware of the possible influence of disrupting factors on the accuracy of DXA.

Keywords Dual-energy X-ray absorptiometry · Severe neurological impairment $\cdot$ Children · Disrupting factors

\section{Introduction}

Reduced bone health in children with severe neurological impairment and intellectual disability (ID) has raised concern and research interest during recent years [1-3]. It is established that children with moderate to severe cerebral palsy (CP), who often experience many additional health problems, have an increased risk of developing low bone mineral density (BMD). They, therefore, have an increased risk of low-impact fractures $[1,4,5]$.

To determine BMD, dual-energy X-ray absorptiometry (DXA) is generally accepted as the method of choice. With DXA, after determining the bone mineral content (BMC) of body parts or the total body, a subsequent BMD is calculated by dividing BMC by bone area. However, it is known 
that the accuracy of BMD outcome in children is diminished by several factors, such as variability in skeletal size and body composition [6,7]. Several studies have reported on additional artefacts and their influences on DXA results in the general population or in other patient groups [8-12]. The shape of the scanning X-ray beam, pencil beam versus fan beam, may also influence the accuracy of the measurement. As its name suggests, pencil-beam scanners use a fine pencil beam of X-rays combined with a single detector scanning the patient in a raster fashion back and forth. While the detector moves over the patient, the body parts not scanned may be fixated to reduce movement artefacts. The fan-beam technology, in comparison, uses a wider X-ray beam that is detected using an array of detectors. The pencil-beam method is found to be more accurate with less interference of magnification errors compared with the fan-beam method $[13,14]$. The most important advantage of the fan-beam technology is that it offers a shorter scan time $[15,16]$. Disrupting factors may lead to both underestimation and/or overestimation of BMD [6, 9, 11, 17-19].

DXA is also used to determine body composition, e.g. lean body mass, percentage body fat (BF). The disrupting factors influence these parameters as well [14].

Operator-related artefacts, e.g. incorrect region of interest or inappropriate reference database, can be minimised by employing an experienced and trained operator who is familiar with the DXA equipment and software [9, 12]. However, patient-related artefacts are more difficult to deal with, e.g. severe contractures or orthopaedic hardware following scoliosis operation $[11,12,20]$. While performing DXA measurements in children with severe neurological impairment and ID, we noticed that disrupting factors are frequently present (Fig. 1). As far as we are aware, there are no studies on the frequency of factors that may negatively influence accuracy of DXA outcomes in children with severe neurological impairment and ID. It is not clear whether these factors may lead to a systematic under-diagnosis or over-diagnosis of low BMD in this group and whether these factors are associated with low BMD. This limits our knowledge of the feasibility of DXA in this specific group of children.

Our main objective was to describe which factors reduce the accuracy of DXA outcome and to determine their frequency in a group of children with severe neurological impairment and ID. To observe whether these factors might lead to systematically skewed outcomes, we studied the correlation between the individual number of disturbing factors and DXA outcome values; total-body BMC, BMC of the extremities, lumbar spine or total-body BMD values, lumbar spine and total-body Z-scores and body-fat percentage. We also investigated whether children with moderate or severe ID and with low or normal BMD differed in the presence of the most prevalent disrupting factors.

\section{Materials and methods}

Study design

This study consisted of two separate parts. First, a checklist with known disrupting factors was developed. Then we assessed the presence of these disrupting factors in 34 children with severe neurological impairment and ID, who underwent DXA examination within the framework of a larger study on validation of nutritional assessment techniques. The framework study was approved by the Dutch Central Committee on Research Involving Human Subjects (The Hague, The Netherlands, P05.0102 C).

\section{Checklist}

We used Medline to develop an overview of reported disrupting factors and artefacts. Disrupting factors according to five experts on (paediatric) DXA measurements were added. The respondents were a paediatric DXA operator, a paediatric endocrinologist, a paediatric radiologist, an internistendocrinologist and a radiotherapist. All had a vast experience with DXA measurements for diagnostic and research purposes (experience, mean 17 years) and two of them were familiar with the target population (years of experience, mean 5.5 years). They were asked to answer the following in a questionnaire:

- Which factors negatively influence the accuracy of DXA results?

- To what extent do these factors disrupt the DXA results in children with severe neurological impairment and ID (from "hardly disrupting" to "extremely disturbing" on a five-point scale).

All disrupting factors and artefacts were recorded in a checklist for clinical purposes (Appendix).

\section{Participants}

Children between 2 and 19 years of age with severe neurological impairment and ID known to have a moderate to severe ID $(\mathrm{IQ}<55)$ and a gross motor functioning classification scale (GMFCS) [21] of level IV or V were recruited through children's day care centres. 
Fig. 1 Two examples of dualenergy X-ray absorptiometry in children with severe neurological impairment and ID. a An 11year-old girl with severe scoliosis. b A 5-year-old girl with an intracorporal medical device
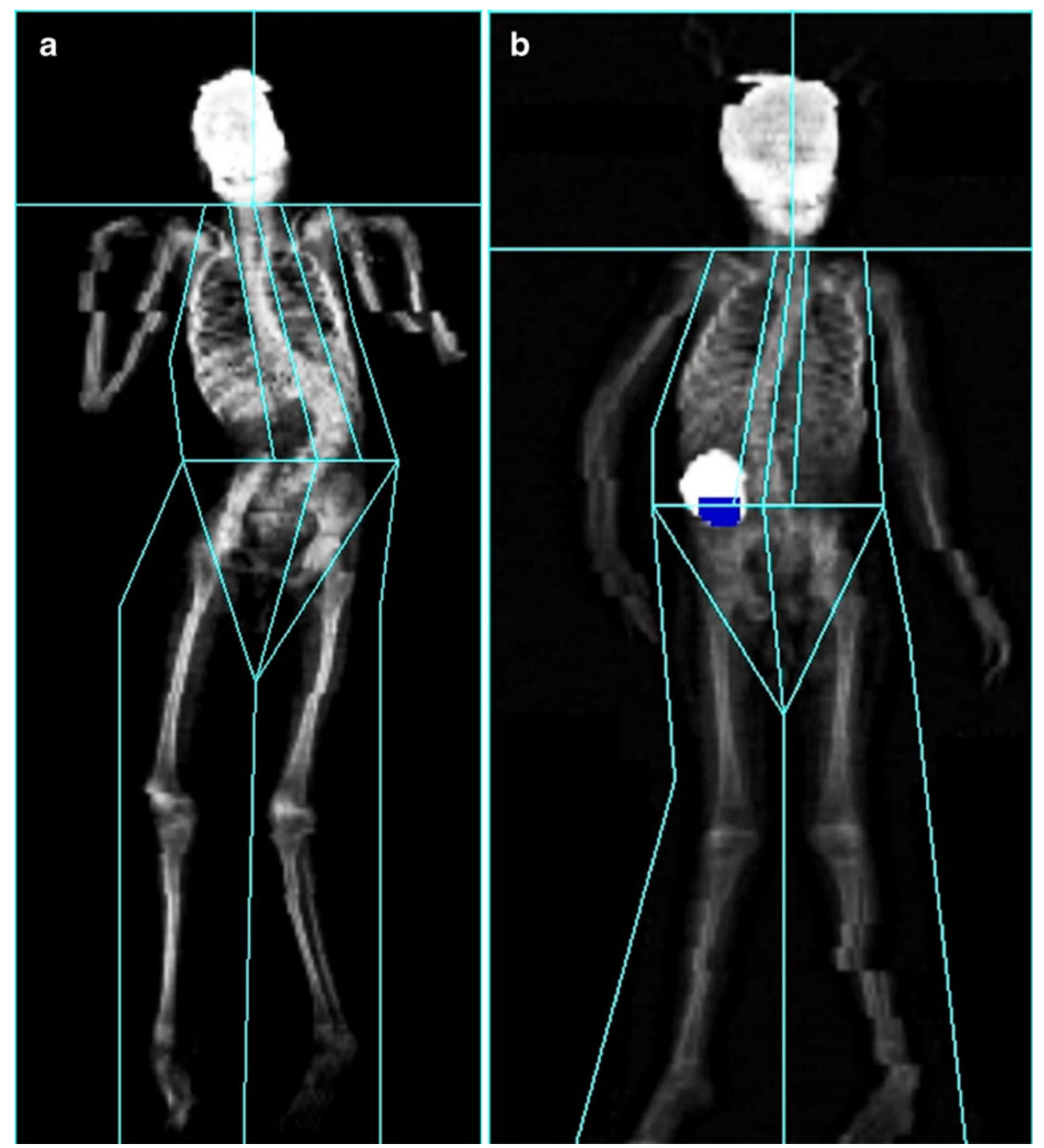

\section{DXA scan}

Measurements of bone mineral content (BMC), bone mineral density (BMD) and BF percentage were performed by pencil-beam DXA (Lunar; DPXL/PED, Madison, Wisconsin, USA). DXA values of the lumbar spine, totalbody and body-fat percentages were compared with normative data of healthy Caucasian children, as obtained by Van der Sluis et al. [22], and were converted to age and genderrelated Z-scores. There were no reference values for BMC values available. Low BMD was diagnosed if a $\mathrm{Z}$-score of -2.0 or below was obtained. High BF was defined as a body-fat Z-score equal to or higher than 2.0. All DXA measurements were done by the same well-trained operator, experienced in working with children with intellectual disabilities. None of the children received sedating medication prior to the measurement. One of the researchers (R.R.) assisted during all DXA measurements and a parent or caregiver, was also present to reassure the child. To prevent movement during the recording, the child was manually immobilised by the researcher and parent/carer. Attention was paid not to influence the DXA measurements. The operator aimed at obtaining an optimal scanning result; therefore, artefacts were removed if possible (e.g. metal objects on clothing) or otherwise excluded from the scan results (e.g. projection of the gastrostomy catheter onto a lumbar vertebra). All artefacts for which adjustment of the scan was needed were counted. 
Evaluation of artefacts and disrupting factors included in the checklist

After the scan, the operator recorded specific details and presence of artefacts on the test outcome form. During DXA measurements, the child's level of movement was recorded on a four-point scale (from 4 points when a child was lying completely still to 1 point when the child was moving to an extreme degree).

Factors regarding growth and nutritional status had been assessed within the framework of the larger study on nutritional assessment techniques [23]. In brief, body height $(\mathrm{cm})$ was measured with a flexible tape line and compared with Dutch reference values as provided by Growth Analyser 3.5 (Dutch Growth Foundation, 2007). A child was diagnosed with "small bones" if body height was below the 5 th centile for age. Triceps and subscapular skin-fold thicknesses ( $\mathrm{mm}$ ) were measured with a Harpenden skin-fold calliper (John Bull, London, United Kingdom); these sites are most commonly included in equations on body fatness. Skin-fold thickness was measured three times at each site. Mean values were calculated and used for further analyses. Centile scores in comparison with matched healthy gender-groups and age-groups were calculated using the Dutch reference values of Gerver and de Bruin [24] and categorised as low ( $\leq 3$ rd centile), normal (between 3 rd and 97th centile) or high ( $\geq 97$ th centile). If there was a substantial discrepancy in outcome between centiles of subscapular and triceps skinfolds (e.g. triceps in the low and subscapular in the normal centile group or triceps in the normal and in the subscapular high centile group), the child was considered to have an aberrant subcutaneous fat distribution.

Medical history and medication were recorded from patient files. Data on lumbar spine surgery, presence of intracorporal devices, use of contrast agents, presence of calcinosis and use of calcium tablets were recorded.

Mobility according to the Gross Motor Function Classification System [21] and the presence of contractures or scoliosis were assessed by observation and performing physical examination if necessary.

\section{Statistical analysis}

Statistical analysis was performed using Statistical Package for Social Sciences 15.0 for Windows (SPSS, Chicago, IL, USA).

Descriptive statistics are reported as number of cases and percentages. Pearson correlations coefficients were calculated for DXA outcome measures (BMC, BMD, BF) and the number of disturbing factors per child. After dichotomising BMD Z-scores in low $(\leq-2)$ and normal $(>-2)$, an unpaired $t$-test was performed to assess the difference in mean number of disturbing factors in these groups.

Fisher exact test was used to determine proportional differences between the presence of disrupting factors in children with moderate and severe ID, low and normal total-body BMD Z-score and low and normal BMD lumbar spine Z-score. $P$ less than 0.05 was considered statistically significant.

\section{Results}

The disrupting factors and artefacts according to literature findings and expert opinion are presented in Table 1.

Information on the presence or absence of all disrupting factors and outcome of the DXA measurement were available from 27/34 children. In three children, skin-fold thickness was not assessed and in four children no information was present on movement during examination; therefore, they were excluded from analysis. Patient characteristics are summarised in Table 2. The children all had moderate to severe IDs as well as severe motor disabilities: most scored level V on the Gross Motor Functioning and Classification Scale [21] and were unable to walk independently.

The mean number of distorting factors and artefacts per child was 5.3 (range 1-8). Five children (18.5\%) had a mean of 4.6 contractures (range 2-8). In ten children, scoliosis was apparent $(37.0 \%)$, and in one child $(3.7 \%)$, the scoliosis was corrected with osteosynthesis materials in situ. An example of DXA measurement of one of the children with severe scoliosis is shown in Fig 1. Fourteen children $(58.8 \%)$ had an intracorporal medical device, all of them in the form of a gastrostomy catheter, but only in two children (7.4\%) did the catheter project onto the lumbar spine. One of these two had, in addition, an intrathecal pump for baclofen medication (Fig. 1). During DXA examination, five children (18.5\%) were completely immobile and 26 children $(81.5 \%)$ were moving with severity of movement varying from some movement to extreme movement. In our study population, 15 children $(55.6 \%)$ had a Z-score lower than -2 SD for length for age and 13 out of these 15 children had a Zscore lower than -2.5 SD. Nine children $(29.0 \%)$ had a subscapular skin-fold above the 97th centile for their age and gender group and 15 children (48.5\%) had a triceps skin-fold on or below the 3rd centile for their age and gender group. After categorising skin-fold outcomes of subscapular and triceps measuring sites in either low $(\leq$ 3 rd centile), normal (between 3 rd and 97th centile) or high ( $\geq 97$ th centile), an aberrant body composition was identified in 21 children $(67.6 \%)$. In none of the children 
Table 1 Factors that might distort the outcome of DXA measurements in children with severe neurological impairment and intellectual disability, including observed frequencies in the study group $(n=27)$

\begin{tabular}{|c|c|c|c|}
\hline Factors & & $\mathrm{n}$ & $\%$ \\
\hline Contractures & & 5 & 19 \\
\hline Scoliosis & & 10 & 37 \\
\hline \multirow[t]{4}{*}{ Movement during measurement } & Complete immobilisation & 5 & 19 \\
\hline & Some movement & 11 & 41 \\
\hline & Considerable movement & 7 & 26 \\
\hline & Extreme movement & 4 & 15 \\
\hline Orthopaedic hardware & & 1 & 3 \\
\hline Aberrant body composition (fat-lean mass) & $\begin{array}{l}\text { Substantial difference between triceps } \\
\text { and subscapular skin-fold centile }\end{array}$ & 18 & 67 \\
\hline Small bones (length for age) & $<5$ th centile for age & 15 & 56 \\
\hline \multirow[t]{3}{*}{ Intracorporal medical devices } & Intrathecal pump & 1 & 4 \\
\hline & Gastrostomy catheter & 14 & 52 \\
\hline & $\begin{array}{l}\text { Gastrostomy catheter with projection } \\
\text { on lumbar spine }\end{array}$ & 2 & 7 \\
\hline (Crush) fractures & & 0 & 0 \\
\hline $\begin{array}{l}\text { Other vertebral anomalies } \\
\text { (e.g. spondylodesis, } \\
\text { osteoarthritis, spinal implants, laminectomy) }\end{array}$ & & 2 & 7 \\
\hline Jewellery or objects on clothing & & 1 & 4 \\
\hline $\begin{array}{l}\text { Dense metal objects (e.g. bullet, } \\
\text { large collection of clips) }\end{array}$ & & 0 & 0 \\
\hline Metastatic lesions & & 0 & 0 \\
\hline $\begin{array}{l}\text { Vascular/aortic calcification or } \\
\text { calcified tendonitis and anostosis }\end{array}$ & & 0 & 0 \\
\hline Calcinosis or calculi & & 1 & 4 \\
\hline $\begin{array}{l}\text { Contrast agents or undissolved } \\
\text { calcium tablets in GI-tract }\end{array}$ & & 0 & 0 \\
\hline
\end{tabular}

did the triceps skin-fold thickness exceed the subscapular skin-fold thickness.

Despite the disrupting factors, BMD results as well as body composition results could be produced for lumbar spine and total body in all 27 children. The mean BMC of the total body was $757 \mathrm{~g}(\mathrm{SD}, 421)$. The mean BMC of the left arm was $36 \mathrm{~g}$ (SD, 30), of the right arm $37 \mathrm{~g}$ (SD, 34), left leg $68 \mathrm{~g}$ (SD 58), right leg $73 \mathrm{~g}$ (SD, 69). The mean BMD Z-score for total-body DXA was -1.30 (SD 1.79) and the mean BMD Z-score for the lumbar spine (L2-L4) was -2.41 (SD 1.18). A significant correlation between absolute BMD values of the total body and of the lumbar spine was observed $(P=0.001)$. This correlation was not present between both BMD Z-scores $(P=0.455)$.

The mean percentage BF measured by DXA $(n=23)$ was $25.2 \%$ (SD, 12.3). Six children (22.2\%) had high $\mathrm{BF}$, defined as a $\mathrm{BF}$ standard deviation score equal to or more than $2 \mathrm{SD}$.

There was no significant correlation between the amount of disturbing factors and the BMC of the total body $(P=0.432)$, or with the BMC of the different extremities (left arm, $P=0.637$; left leg, $P=0.743$; right arm, $P=0.543$; right leg, $P=0.929$ ).
The BMD of the total body $(P=0.226)$, the BMD Z-score of the total body $(P=0.755)$, the BMD value of the lumbar spine $(P=0.492)$ and the BMD Z-score of the lumbar spine $(P=$ 0.192) were not correlated with the number of disrupting factors as well. Also, no correlation was found between BF percentage and the amount of disrupting factors $(P=0.148)$.

Table 2 Patient characteristics $(n=27)$

\begin{tabular}{llrrr}
\hline & & $n$ & $\%$ & Mean (range) \\
\hline Gender & Female & 14 & 51.9 & \\
& Male & 13 & 48.1 & \\
Age, years & & & & $8.5(3-17)$ \\
Severity of ID & Moderate (IQ<50) & 2 & 7.4 & \\
& Severe (IQ<35) & 25 & 92.6 & \\
GMFCS & Level IV & 2 & 7.4 & \\
& Level V & 25 & 92.6 &
\end{tabular}

Body weight, $\mathrm{kg}$

$24.4(10-55)$

GMFCS Gross Motor Function Classification System, ID intellectual disability, $I Q$ intelligence quotient 
Table 3 Mean number of disturbing factors in children with and without low bone mineral density (BMD; $n=27)$

$* P=0.65, * * P=0.24$

\begin{tabular}{llllll}
\hline & \multicolumn{2}{l}{ Total-body BMD Z-score } & & \multicolumn{2}{l}{ Lumbar spine BMD Z-score } \\
\cline { 2 - 3 } & $\begin{array}{l}\text { Low }(\leq-2.0) \\
(n=11)\end{array}$ & $\begin{array}{l}\text { Normal }(>-2.0) \\
(n=16)\end{array}$ & & $\begin{array}{l}\text { Low }(\leq-2.0) \\
(n=18)\end{array}$ & $\begin{array}{l}\text { Normal }(>-2.0) \\
(n=9)\end{array}$ \\
\hline $\begin{array}{c}\text { Number of disturbing } \\
\text { factors, mean (SD) }\end{array}$ & $5.5(2.25)$ & $5.1(1.50)^{*}$ & & $5.6(1.98)$ & $4.7(1.32)^{* *}$ \\
\hline
\end{tabular}

Comparison of children with and without low BMD (defined as Z-score $<-2.0$ ) in total body or lumbar spine showed no significant difference in mean number of disrupting factors (Table 3). There were no significant proportional differences in presence of scoliosis, movement during measurement, aberrant body composition, small length and presence of a gastrostomy catheter when comparing children with moderate to severe ID, children with low and normal total-body BMD Zscore or children with low and normal BMD lumbar spine Zscore (Table 4).

\section{Discussion}

As expected, factors that may negatively influence the accuracy of DXA measurements were frequently present in children with severe neurological impairment and ID, with a mean of 5.3 factors in 27 children. The most frequently occurring factors were movement during measurement, scoliosis, contractures, gastrostomy catheters, aberrant body composition and a height below the 5 th centile for age. The prevalences of these factors did not differ between children with low or normal BMD. We found no systematic overestimation or underestimation of BMC, BMD or BF outcome relating to the amount of disrupting factors.

Table 4 Proportional differences between presence of scoliosis, movement during measurement, aberrant body composition, small length and presence of a gastrostomy catheter in children with moderate to
Therefore, it remains unknown to what extent DXA outcomes are influenced if one or more artefacts are present.

Published studies on disrupting factors in DXA examination are mostly descriptive and frequently performed in older patients or postmenopausal women $[10,17,18,25,26]$. Most studies describe only one of the factors in detail and we found no study determining the total amount of disrupting factors present in specific patient groups. Therefore, it remains unknown whether the number of disrupting factors is higher in our population than in others. Our finding of a mean of five disrupting factors per child, however, implies that DXA outcomes in children with severe neurological impairment and ID may be prone to inaccuracy. The lack of correlation between the amount of disrupting factors and BMD might be explained by the relatively small study population $(n=27)$ and the fact that disrupting factors may lead to both overestimation and underestimation of bone density [6, 9, 11, 17-19, 27]. The question whether BMD outcome in children with severe neurological impairment and ID deviates in a systematic way as a result of disrupting factors can, therefore, not be thoroughly answered. Additional information on the presence of artefacts is, however, important to interpret the results of the individual bone

severe intellectual disability (ID), low and normal total-body bone mineral density (BMD) Z-score and low and normal BMD lumbar spine Z-score $(n=27)$

\begin{tabular}{|c|c|c|c|c|c|c|c|c|c|}
\hline & \multicolumn{3}{|l|}{ ID } & \multicolumn{3}{|c|}{ Total-body BMD Z-score } & \multicolumn{3}{|c|}{ Lumbar spine BMD Z-score } \\
\hline & $\begin{array}{l}\text { Moderate } \\
(n=2)\end{array}$ & $\begin{array}{l}\text { Severe } \\
(n=25)\end{array}$ & $\begin{array}{l}\text { Fisher } \\
\text { exact test }\end{array}$ & $\begin{array}{l}\text { Low }(\leq-2.0) \\
(n=11)\end{array}$ & $\begin{array}{l}\text { Normal }(>-2.0) \\
(n=16)\end{array}$ & $\begin{array}{l}\text { Fisher } \\
\text { exact test }\end{array}$ & $\begin{array}{l}\text { Low }(\leq-2.0) \\
(n=18)\end{array}$ & $\begin{array}{l}\text { Normal }(>-2.0) \\
(n=9)\end{array}$ & $\begin{array}{l}\text { Fisher } \\
\text { exact test }\end{array}$ \\
\hline Scoliosis & 0 & 10 & 0.516 & 5 & 5 & 0.687 & 8 & 2 & 0.406 \\
\hline $\begin{array}{l}\text { Movement during } \\
\text { measurement }\end{array}$ & 2 & 20 & 1.000 & 9 & 13 & 1.000 & 14 & 8 & 0.636 \\
\hline $\begin{array}{l}\text { Aberrant body } \\
\text { composition }\end{array}$ & 0 & 18 & 0.103 & 6 & 12 & 0.411 & 12 & 6 & 1.000 \\
\hline $\begin{array}{l}\text { Small length } \\
(<5 \text { th centile })\end{array}$ & 1 & 14 & 1.000 & 8 & 7 & 0.239 & 11 & 4 & 0.448 \\
\hline Gastrostomy catheter & 0 & 14 & 0.222 & 5 & 8 & 0.704 & 9 & 5 & 1.000 \\
\hline
\end{tabular}


density and body composition measurements, not only for single measurements but especially for repeated measurements in which the presence of disrupting factors may differ.

The power and strength of the statistical techniques performed in this pilot study were limited by the small study population, e.g. regression analysis and prediction models could not be used because of the small sample size. We, therefore, recommend a study to be conducted with a more appropriate sample size so that more sophisticated statistical techniques can be used to further clarify the associations between disrupting factors and DXA outcomes.

Most of the reported disrupting factors are hard to avoid, but movement during measurement might be diminished by giving sedative medication in advance [27] or by placing sand cushions or straps to prevent movement. However, considering that these measures impose restraints that undoubtedly will increase stress, and knowing that sedatives might cause side effects like cardiorespiratory depression or vomiting and aspiration [28], the advantages and disadvantages of those measures need to be assessed on an individual basis. When, despite measures to prevent it, considerable or extreme movements occur during measurement, DXA outcome is unreliable. The measurement should either be repeated when the child is more at ease or an alternative diagnostic method less susceptible to movement (e.g. quantitative ultrasound or automated radiogrammetry) should be used.

In our study, a pencil-beam DXA method was used. With a pencil-beam DXA, the body parts not being scanned at that moment can be manually fixated to prevent movement. This enhances the accuracy of the bone and soft tissue measurements. The pencil-beam method, therefore, may be more accurate than the fan-beam method in severely handicapped children.

The accuracy of DXA is largely dependent on the experience of the operator, appropriate regions of interest and, when possible, artefact removal. We, therefore, recommend that all clinical centres where DXA is performed in children with severe neurological impairment and ID designate an operator with special interest to gain experience with these children. The operator needs to routinely record disrupting factors and present these together with the scan results to the referring physician. It may be recommended that the checklist developed as part of our study (Appendix) is adopted by manufacturers of DXA systems as part of the results printout.

Regarding intracorporal devices and metallic implants, we feel that the usability of DXA can be improved if the software enables more accurate corrections. After deleting the very high density pixels (caused by these artefacts) from the scans, alternative subregions that give an estimate of its "BMC equivalent" should be added to reduce interference with the DXA outcome. It is recommended that the manufacturers adapt their DXA software accordingly.

In The Netherlands, it is common to measure bone density in children by performing DXA of the lumbar spine and total body [22]. However, Henderson et al. [29] have indicated that measurement of the BMD of the distal femur projected in a lateral plane in children with moderate to severe $\mathrm{CP}$ or muscular dystrophy has a strong correlation with fracture history. This specific scanning technique may diminish the amount of disturbing factors as well, e.g. no projection of scoliosis or intracorporal devices on the lumbar spine, fewer positioning problems due to contractures and probably less movement during examination because patients are lying on their side. Development of reference values for distal femur BMD for the different DXA devices and standardisation of the measurement procedure may be an important step in standardising diagnosis of low bone mineral density in children with severe neurological impairment and ID.

\section{Conclusion}

In children with severe neurological impairment and ID, frequently occurring disrupting factors may influence the feasibility of DXA and the accuracy of its outcome. Because treatment of low bone density in practice is reserved for children with (low impact) fractures, this distortion presumably has had limited effect on treatment frequency. However, alterations in artefacts over time may complicate comparison of successive outcome values in an individual child. In addition, the effectiveness of preventive measures can only be determined if accurate and reliable bone density measurements are available. Therefore, either more information on the impact of individual disrupting factors is necessary, or other methods or localisations for bone density measurement less prone to distortion are needed for this population.

Acknowledgements We would like to thank the following people for their contribution to this study and sharing their experiences with us: Mrs. J.P. Sluimer (paediatric DXA operator, Erasmus MC, University Medical Centre, Rotterdam), Dr. A.M. Boot (paediatric-endocrinologist, University Medical Centre Groningen), Dr. M.C. Zillikens (internistendocrinologist, Erasmus MC, University Medical Centre, Rotterdam) and Ir. P.P.M. Kooij (radiotherapist, Erasmus MC, University Medical Centre, Rotterdam).

Conflicts of interest None.

Open Access This article is distributed under the terms of the Creative Commons Attribution Noncommercial License, which permits any noncommercial use, distribution and reproduction in any medium, provided the original author(s) and source are credited. 


\section{Appendix}

Checklist of artefacts and disrupting factors during DXA in children with severe neurological impairment and intellectual disability

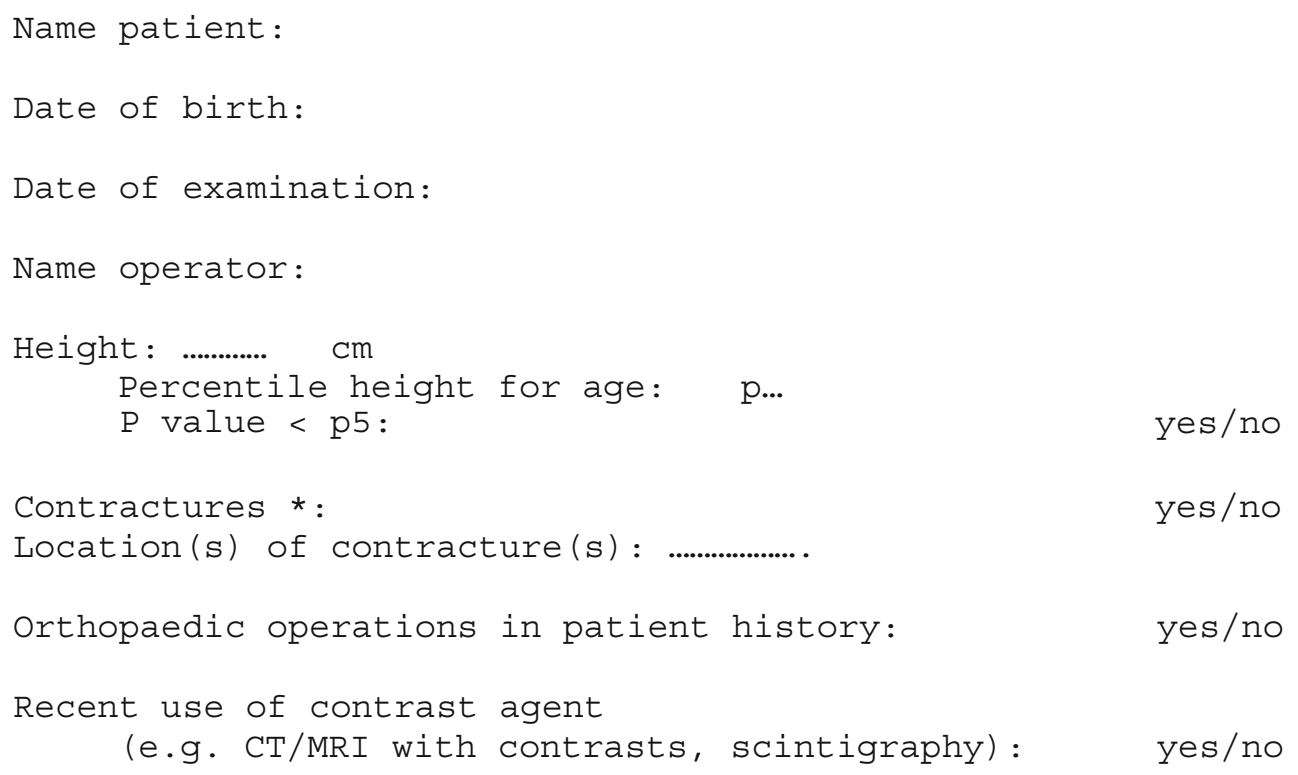


Jewellery or metal objects on clothing:

yes/no

Dense metal objects present

(e.g. bullets, collection operation clips):

yes/no

Calcinosis of calculi present:

yes/no

Undissolved calcium tablets in GI tract present: yes/no

Calcifications present (e.g. vascular/aorta, tendinitis): yes/no

Metastatic lesions: $\quad$ yes/no

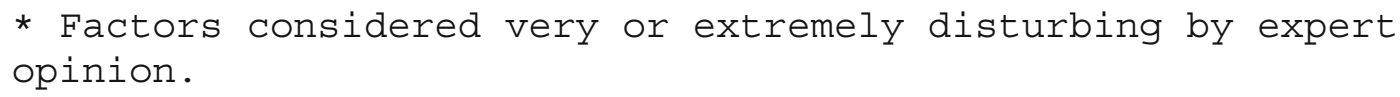

One or more 'yes' answers on this checklist may implicate that

the DXA outcome is less reliable; the extent of disruption

depends on the factor involved and the degree of disturbance

(e.g. movement).

In case of doubt concerning the interpretation of these

results contact the operator for consultation.

\section{References}

1. Henderson RC, Lin PP, Greene WB (1995) Bone-mineral density in children and adolescents who have spastic cerebral palsy. J Bone Joint Surg Am 77:1671-1681

2. Zacharin M (2004) Current advances in bone health of disabled children. Curr Opin Pediatr 16:545-551

3. Hough JP, Boyd RN, Keating JL (2010) Systematic review of interventions for low bone mineral density in children with cerebral palsy. Pediatrics 125:e670-678.

4. Henderson RC, Kairalla JA, Barrington JW et al (2005) Longitudinal changes in bone density in children and adolescents with moderate to severe cerebral palsy. J Pediatr 146:769-775

5. Henderson RC, Lark RK, Gurka MJ et al (2002) Bone density and metabolism in children and adolescents with moderate to severe cerebral palsy. Pediatrics 110:e5

6. Binkovitz LA, Henwood MJ, Sparke P (2008) Pediatric DXA: technique, interpretation and clinical applications. Pediatr Radiol 38(Suppl 2):S227-S239

7. Wren TA, Liu X, Pitukcheewanont P et al (2005) Bone densitometry in pediatric populations: discrepancies in the diagnosis of osteoporosis by DXA and CT. J Pediatr 146:776-779

8. Fewtrell MS, British P, Adolescent Bone G (2003) Bone densitometry in children assessed by dual $\mathrm{x}$ ray absorptiometry: uses and pitfalls. Arch Dis Child 88:795-798
9. Jacobson JA, Jamadar DA, Hayes CW (2000) Dual X-ray absorptiometry: recognizing image artifacts and pathology. AJR 174:1699-1705

10. Kirac FS, Yuksel D, Yaylali OT (2001) Pitfalls in the measurement of bone mineral density by the dual-energy X-ray absorptiometric method. Clin Nucl Med 26:874-875

11. Morgan SL, Lopez-Ben R, Nunnally N et al (2008) The effect of common artifacts lateral to the spine on bone mineral density in the lumbar spine. J Clin Densitom 11:243-249

12. Theodorou DJ, Theodorou SJ (2002) Dual-energy X-ray absorptiometry in clinical practice: application and interpretation of scans beyond the numbers. Clin Imaging 26:43-49

13. Ioannidou E, Padilla J, Wang J et al (2003) Pencil-beam versus fan-beam dual-energy X-ray absorptiometry comparisons across four systems: appendicular lean soft tissue. Acta Diabetol 40 (Suppl 1):S83-S85

14. Hammami M, Koo WW, Hockman EM (2004) Technical considerations for fan-beam dual-energy $\mathrm{x}$-ray absorptiometry body composition measurements in pediatric studies. JPEN 28:328-333

15. Koo WW, Walters J, Bush AJ (1995) Technical considerations of dual-energy X-ray absorptiometry-based bone mineral measurements for pediatric studies. J Bone Miner Res 10:1998-2004

16. Koo WW, Hammami M, Hockman EM (2003) Interchangeability of pencil-beam and fan-beam dual-energy X-ray absorptiometry measurements in piglets and infants. Am J Clin Nutr 78:236-240 
17. Meirelles ES, Borelli A, Camargo OP (1999) Influence of disease activity and chronicity on ankylosing spondylitis bone mass loss. Clin Rheumatol 18:364-368

18. Morgan SL, Lopez-Ben R, Nunnally N et al (2008) Black hole artifacts - a new potential pitfall for DXA accuracy? J Clin Densitom 11:266-275

19. Ott SM, Ichikawa LE, LaCroix AZ et al (2009) Navel jewelry artifacts and intravertebral variation in spine bone densitometry in adolescents and young women. J Clin Densitom 12:84-88

20. Binkovitz LA, Henwood MJ, Sparke P (2007) Pediatric dualenergy X-ray absorptiometry: technique, interpretation, and clinical applications. Semin Nucl Med 37:303-313

21. Rosenbaum PL, Palisano RJ, Bartlett DJ et al (2008) Development of the Gross Motor Function Classification System for cerebral palsy. Dev Med Child Neurol 50:249-253

22. van der Sluis IM, de Ridder MA, Boot AM et al (2002) Reference data for bone density and body composition measured with dualenergy $x$ ray absorptiometry in white children and young adults. Arch Dis Child 87:341-347; discussion 341-347.

23. Rieken R, van Goudoever JB, Schierbeek H et al (2011) Measuring body composition and energy expenditure in children with severe neurologic impairment and intellectual disability. Am J Clin Nutr 94:759-766

24. Gerver W (2001) Paediatric morphometrics: a reference manual, 2nd edn. Universitaire Pers Maastricht, Maastricht

25. Binkley N, Krueger D, Vallarta-Ast N (2003) An overlying fat panniculus affects femur bone mass measurement. J Clin Densitom 6:199-204

26. Morgan SL, Lopez-Ben R, Nunnally N et al (2008) The effect of common artifacts lateral to the spine on bone mineral density in the lumbar spine. J Clin Densitom 11:243-249.

27. Kilpinen-Loisa P, Paasio T, Soiva M et al (2010) Low bone mass in patients with motor disability: prevalence and risk factors in 59 Finnish children. Dev Med Child Neurol 52:276-282

28. Zier JL, Rivard PF, Krach LE et al (2008) Effectiveness of sedation using nitrous oxide compared with enteral midazolam for botulinum toxin A injections in children. Dev Med Child Neurol 50:854-858

29. Henderson RC, Berglund LM, May R et al (2010) The relationship between fractures and DXA measures of BMD in the distal femur of children and adolescents with cerebral palsy or muscular dystrophy. J Bone Miner Res 25:520-526 